\title{
Prevalence of Water Pipe Use and Its Correlates in Iranian Women of Reproductive Age in Tehran: A Population-Based Study
}

\author{
Azam Baheiraei $^{\mathrm{a}, \mathrm{b}}$ Mojgan Mirghafourvand ${ }^{\mathrm{a}}$ Saharnaz Nedjat ${ }^{\mathrm{c}}$

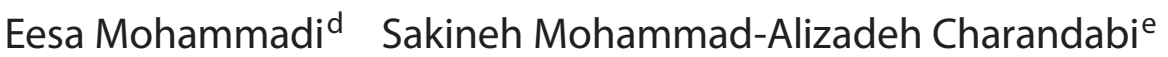 \\ ${ }^{a}$ Department of Reproductive Health, ${ }^{b}$ Center for Community-Based Participatory Research, ${ }^{c}$ Department of \\ Epidemiology and Biostatistics, Tehran University of Medical Sciences, ${ }^{d}$ Department of Nursing, Tarbiat Modares

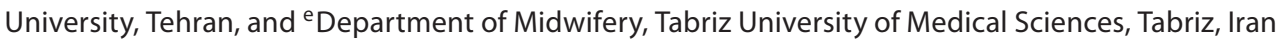

\section{Key Words}

Prevalence $\cdot$ Sociodemographic factors $\cdot$ Water pipe $\cdot$

Iranian women $\cdot$ Reproductive age

\begin{abstract}
Objective: The objective of this study was to determine the prevalence of water pipe smoking and its associated sociodemographic factors among Iranian women of reproductive age in Tehran. Subjects and Methods: This was a population-based cross-sectional study of 1,359 Iranian women aged $15-49$ years. The multistage random cluster technique was used to obtain the sample. Questionnaire-based interviews with questions relating to water pipe smoking and sociodemographic variables were used to collect the data. The multivariate logistic regression model was used to analyse the relationships between the dependent variable (water pipe smoking) and the independent variables (sociodemographic characteristics). Results: The prevalence of water pipe smoking was $6.3 \%$ among Iranian women. Water pipe smoking was more likely in the age range of 15-24 years [odds ratio $(\mathrm{OR})=4.8,95 \%$ confidence interval $(95 \% \mathrm{Cl})=$ 2.7-8.6] compared to the age range of 35 years or older, in women with a university education $(\mathrm{OR}=1.9,95 \% \mathrm{Cl}=1.3-$
\end{abstract}

3.0) compared to women with a high-school diploma or lower, and in women with an average crowding index score $(\mathrm{OR}=4.7,95 \% \mathrm{Cl}=2.1-10.6)$ compared to women living in small families. Conclusion: The findings of this study show that Iranian women with a university education and the younger age group (15-24 years) were at most risk of water pipe smoking. The findings of this study about associated factors may contribute to the development of efficient health promotion programmes for the prevention and cessation of water pipe smoking. Copyright $\Theta 2012$ S. Karger AG, Basel

\section{Introduction}

Water pipe smoking is becoming an increasing public health issue [1]. Studies, therapies and regulations on tobacco smoking have focused primarily on cigarettes while women in several developing countries tend to prefer water pipes over cigarettes [2]. Different regions designate the water pipe by different names, such as nargile, hookah, shisha, hubbly-bubbly, hubble-bubble, oriental pipe, boory, glase base, goza and mada'a. In Iran, it is known as ghalyan [3,4]. Misunderstandings about the

\section{KARGER}

Fax +41613061234

E-Mail karger@karger.ch

www.karger.com
(C) 2012 S. Karger AG, Basel

1011-7571/12/0214-0340\$38.00/0

Accessible online at:

www.karger.com/mpp
Azam Baheiraei, MPH, PhD

Department of Reproductive Health

Tehran University of Medical Sciences

P.O. Box 15745-1453, Tehran (Iran)

Tel. +98 216694 3187, E-Mail baheiraei@tums.ac.ir 
dangers and complications of water pipe smoking are common. Unfortunately, most water pipe smokers are unaware of the dangers of water pipe smoking and consider it a safe alternative to cigarette smoking $[2,5,6]$. However, smoke from the water pipe contains many of the carcinogens and toxic elements found in cigarette smoking, such as monoxide, nicotine, tar and heavy metals $[3,7]$, and therefore may lower quality of life $[8,9]$ as it is associated with various poor-health outcomes [10, 11]. A recent systematic review of the health effects of water pipe smoking showed that it was significantly associated with lung cancer, respiratory illness, low birth weight and periodontal disease [12].

Water pipe smoking has become popular among women in Middle Eastern countries during the 19th century [13] as exemplified by Kuwait (79\%). In a study in Kuwait, $79.9 \%$ of water pipe smokers were women while $20.1 \%$ were men [14]. In a survey conducted in Jordan, 53\% female versus $21 \%$ male smoking students preferred the water pipe [15]. In Iran, $17 \%$ women versus $6.2 \%$ men preferred the water pipe [16]. The preference for water pipe smoking in Middle Eastern countries could be ascribed to a stigma associated with cigarette smoking [17]. Considering the increasing use of the water pipe in the Eastern Mediterranean region and women's preference for water pipe smoking, further studies are needed on this issue.

In Iran, water pipe smoking is re-emerging as a common leisure time activity; however, in contrast to cigarette smoking, there have only been a few studies on water pipe smoking $[8,9]$. The prevalence of water pipe smoking has been determined during pregnancy in southern Iran [18], but no study has been conducted to address water pipe smoking and its associated factors during the reproductive age. Most water pipe users are within this age group, and there are 21 million women of reproductive age (15-49 years) in Iran, and 3.8 million (about 18\%) of these women live in Tehran [19]. It is essential to have a better understanding of water pipe smoking, particularly among women. Because of the large population of women of reproductive age in Iran, we have conducted this study in order to determine the prevalence of water pipe smoking and its associated sociodemographic factors among Iranian women of reproductive age.

\section{Subjects and Methods}

This was a population-based cross-sectional study of 1,359 women of 15-49 years of age in Tehran in 2010. Inclusion criteria were having Iranian nationality, speaking Persian, being aged 15-
49 years and residing in Tehran. Exclusion criteria were being pregnant or in the postpartum period. Female interviewers gathered data using face-to-face interviews. We obtained informed consent from all of the participants. The Ethics Committee of the Tehran University of Medical Sciences approved the protocol of this study.

\section{Sampling and Data Collection}

Multistage cluster sampling technique was used to obtain the number of participants in Tehran. Tehran is the largest city and capital of Iran and is divided into 22 municipal districts. Initially, using probability sampling weighted with the number of families in each district (proportional to size sampling), we selected 135 domains and one block was randomly selected from each domain. Subsequently, using systematic sampling, we selected 10 families from each block. Once the families of each block were selected, a woman aged 15-49 years was asked to answer the questions for the family. The sample population was 1,359 women of reproductive age. If the number of units in a block did not reach the number required (10 persons), an adjacent block supplied the extra units needed. In order to adopt a consistent approach to selecting units from adjacent blocks, the interviewers were trained to select the extra units necessary from the block northeast of the originally sampled block. After receiving training for interviewing and data collection, female interviewers conducted the interviews. A supervisory team monitored the entire study to control the quality of the data. In addition, two expert reviewers were invited to review the completed questionnaires.

The interviewers administered the questionnaire and recorded the information. The questionnaire included questions about water pipe smoking and sociodemographic characteristics, including age, marital status, education, occupation, income, measures of crowding, measures of wealth, ethnicity, body mass index (BMI) and spouse's level of education and occupation for married participants. Current female water pipe smokers were defined as women who had smoked on at least 1 day in the 30 days prior to the survey. The content and face validity of the questionnaire was provided by content and lay experts while the reliability of the questionnaire was assessed through test-retest. The crowding index was determined by dividing the number of family members by the number of rooms, excluding the bathroom. We then categorized the crowding index into three levels of crowding, i.e. low crowding: fewer than 2 persons per room; average crowding: $2-3$ persons per room and high crowding: more than 3 persons per room.

In order to calculate the wealth index, respondents were asked whether or not they had separate kitchens or bathrooms in the house and whether or not they owned various items, such as a computer, a washing machine, a freezer, a vacuum cleaner, a dishwasher, a personal car, a telephone, a video player, a television and a mobile phone. Principal component analysis was used to analyse the wealth data, and a wealth index was created. Participants were subsequently categorized as very poor, poor, average, rich, or very rich, according to the index. BMI was calculated using data on weight $(\mathrm{kg})$ divided by square of height $\left(\mathrm{m}^{2}\right)$. Based on the classification of the World Health Organization, the BMI scores were then categorized as underweight: less than 18.5, normal range: 18.5-24.9, overweight: $25-29.9$, and obese $(\geq 30)$ [20]. 


\section{Data Analysis}

Descriptive analysis, including an examination of variable frequencies and percentages, means and standard deviations were used to describe the data. In order to examine the relationship between water pipe smoking and sociodemographic characteristics, we used the $\chi^{2}$ test to determine the correlations between individual explanatory variables and water pipe smoking, followed by multiple logistic regression with backward elimination to determine the influence of each sociodemographic factor on water pipe smoking. Independent variables with $p$ values of less than 0.2 for the $\chi^{2}$ test were entered into the regression model. If two independent variables had a strong collinear relationship, one was selected and included in the multiple logistic regression model. Therefore, the occupation variable was not included in the model due to its collinearity with the 'level of education' variable. SPSS software version 16 was used to analyse the data.

\section{Results}

The result of the test-retest model for determining reliability showed that the intra-class correlation coefficient was 0.97 . As table 1 depicts, 541 (39.8\%) of the surveyed women were aged 35 years or older, with a mean age of $31.9 \pm 9.5$ years. Nine hundred and fifty-seven (70\%) women were married and 886 (64.1\%) were housewives. Almost 965 (71\%) had obtained high-school education or attended university; $338(30 \%)$ were poor, according to the wealth index, and 611 (46.6\%) lived in families with low crowding. Half of the women $(657,50 \%)$ had a normal BMI, with a sample mean BMI of $25.3 \pm 5$. Among the married participants, 661 (67.1\%) of the spouses had a high-school education or higher, and 417 (43.4\%) worked in the private sector.

\section{Prevalence of Water Pipe Smoking and Its Associated}

Sociodemographic Factors

Eighty-six women $(6.3 \%)$ in the sample reported that they currently smoked a water pipe and 32 (37.3\%) had smoked a water pipe for at least 2 years. The results of the $\chi^{2}$ test indicated that water pipe smoking is significantly related to age, marital status, occupation ( $\mathrm{p}<$ $0.001)$, education, spouse's occupation and BMI $(\mathrm{p}<$ 0.05 ) (table 1). In the multivariate logistic model, water pipe smoking was associated with three sociodemographic variables: 15-24 years of age, compared to 35 years or older (odds ratio, $\mathrm{OR}=4.8$ ); having a university education, compared to a high-school or lower level of education $(\mathrm{OR}=1.9)$, and reporting an average crowding index, compared to those in low-crowding families $(\mathrm{OR}=4.7)($ table 2$)$.
Table 1. Frequency of water pipe smoking based on the participants' sociodemographic characteristics

\begin{tabular}{|c|c|c|}
\hline Characteristic $^{1}$ & $\begin{array}{l}\text { Number of } \\
\text { participants }\end{array}$ & $\begin{array}{l}\text { Frequency of water } \\
\text { pipe use }\end{array}$ \\
\hline \multicolumn{3}{|l|}{ Age } \\
\hline $15-24$ years & $350(25.8)$ & $48(13.8)^{* *}$ \\
\hline $25-34$ years & $468(34.4)$ & $21(4.6)$ \\
\hline$\geq 35$ years & $541(39.8)$ & $17(3.2)$ \\
\hline \multicolumn{3}{|l|}{ Marital status } \\
\hline Single & $360(26.6)$ & $43(12)^{* *}$ \\
\hline Married & $957(70.8)$ & $39(4.2)$ \\
\hline Divorced & $17(1.3)$ & $4(23.5)$ \\
\hline Widowed & $18(1.3)$ & 0 \\
\hline \multicolumn{3}{|l|}{ Education } \\
\hline Illiterate & $23(1.7)$ & $1(4.3)^{*}$ \\
\hline Elementary school & $111(8.2)$ & $2(1.8)$ \\
\hline Secondary school & $170(12.5)$ & $8(4.8)$ \\
\hline Some high school & $86(6.3)$ & $41(4.8)$ \\
\hline High-school diploma & $510(37.6)$ & $29(5.8)$ \\
\hline University & $455(33.6)$ & $42(9.3)$ \\
\hline \multicolumn{3}{|l|}{ Occupation } \\
\hline Housewife & $866(64.1)$ & $31(3.7)^{* *}$ \\
\hline Employed & $207(15.3)$ & $21(10.3)$ \\
\hline Student & $247(18.3)$ & $33(13.4)$ \\
\hline Unemployed & $32(2.4)$ & $1(3.1)$ \\
\hline \multicolumn{3}{|l|}{ Sufficiency of income } \\
\hline Absolutely not & $199(14.9)$ & $13(6.7)$ \\
\hline To some extent & $928(69.3)$ & $56(6.1)$ \\
\hline Completely & $213(15.9)$ & $16(7.6)$ \\
\hline \multicolumn{3}{|l|}{ Crowding index } \\
\hline Low & $611(46.6)$ & $29(4.8)$ \\
\hline Average & $535(40.8)$ & $43(8.1)$ \\
\hline High & $164(12.5)$ & $9(5.6)$ \\
\hline \multicolumn{3}{|l|}{ Wealth index } \\
\hline Very poor & $141(12.2)$ & $12(5.4)$ \\
\hline Poor & $338(29.3)$ & $20(9.0)$ \\
\hline Average & $216(18.8)$ & $11(5.1)$ \\
\hline Rich & $227(19.7)$ & $18(5.3)$ \\
\hline Very rich & $230(20.0)$ & $10(7.1)$ \\
\hline \multicolumn{3}{|l|}{ BMI, $\mathrm{kg} / \mathrm{m}^{2}$} \\
\hline$<18.5$ & $66(5.2)$ & $7(10.8)^{*}$ \\
\hline $18.5-24.9$ & $657(50.9)$ & $53(8.2)$ \\
\hline $25-29.9$ & $366(28.3)$ & $17(4.7)$ \\
\hline$\geq 30$ & $202(15.6)$ & $7(3.5)$ \\
\hline \multicolumn{3}{|l|}{ Ethnicity } \\
\hline Persian & $851(62.6)$ & $50(6.0)$ \\
\hline Azari & $380(28.0)$ & $31(8.3)$ \\
\hline Other & $111(8.3)$ & $5(4.6)$ \\
\hline \multicolumn{3}{|l|}{ Spouse's education ${ }^{2}$} \\
\hline Illiterate & $8(0.8)$ & 0 \\
\hline Elementary school & $107(10.9)$ & $3(2.8)$ \\
\hline Secondary school & $159(16.1)$ & $4(2.6)$ \\
\hline Some high school & $50(3.7)$ & $1(2.0)$ \\
\hline High school diploma & $380(38.6)$ & $17(4.6)$ \\
\hline University & $281(28.5)$ & $15(5.5)$ \\
\hline \multicolumn{3}{|l|}{ Spouse's occupation ${ }^{2}$} \\
\hline Unemployed & $19(2.0)$ & $3(15.8)^{*}$ \\
\hline Worker & $127(31.2)$ & $4(3.2)$ \\
\hline Clerk & $363(37.8)$ & $11(3.1)$ \\
\hline Private sector & $417(43.4)$ & $21(5.2)$ \\
\hline Experts/managers & $44(3.5)$ & 0 \\
\hline
\end{tabular}

Figures in parentheses are percentages. ${ }^{*} \mathrm{p}<0.05 ;{ }^{*} \mathrm{p}<0.001$

${ }^{1}$ All variables except age include missing cases.

${ }^{2}$ This variable only applies to married participants. 
Table 2. Multivariate logistic regression analysis for factors associated with water pipe use

\begin{tabular}{ll}
\hline Variable & $\begin{array}{l}\text { Adjusted OR } \\
(95 \% \mathrm{CI})\end{array}$ \\
\hline $\begin{array}{l}\text { Age, years } \\
\quad 35\end{array}$ & 1 \\
$25-34$ & $1.5(0.8-2.8)$ \\
$15-24$ & $4.8(2.7-8.6)^{*}$ \\
Education & 1 \\
$\quad$ High school diploma or lower & $1.9(1.3-3.0)^{* *}$ \\
University & 1 \\
Spouse's occupation & $3.9(0.6-23.2)$ \\
Clerk & $1.3(0.4-4.6)$ \\
Unemployed & $2.1(0.9-4.5)$ \\
Worker & 0.000 \\
Private sector & \\
Expert/manager & 1 \\
Crowding index & $4.7(2.1-10.6)^{*}$ \\
Low & $2.4(0.6-9.8)$ \\
Average & \\
High & \\
\hline * $<<0.001 ;{ }^{* *} \mathrm{p}<0.01$. &
\end{tabular}

\section{Discussion}

The popularity of water pipe smoking in Mediterranean countries and other regions of the world created a new challenge for public health. In the present study, $6.3 \%$ of the women in the sample reported that they currently smoked a water pipe. Age, education and crowding index correlated with water pipe smoking.

The $6.3 \%$ prevalence of water pipe smoking in this study is similar to that reported by Sahraian et al. [21] among medical students in Shiraz (the third largest city of Iran). However, this prevalence is higher than the $0.6 \%$ reported for Central Iran (Isfahan, Najafabad, Arak). It is also higher than the 3.5\% reported for men and the $1.9 \%$ reported for women in a national survey of all Iranian provinces [17]. However, other studies from southern areas of Iran among pregnant women in rural areas of southern Iran reported a higher prevalence rate of $8 \%$ [18] and $17 \%$ among elderly women in Bander Abbas [16]. The high prevalence of water pipe smoking in the southern provinces of Iran may be due to their proximity to Arab countries as high prevalences of water pipe smoking have been reported (25.6\%) in Lebanon [22], (36.8\%) Jordan [15], (37.8\%) Egypt [23], and (45\%) Kuwait [14]. Apparently, water pipe smoking is becoming a behavioural norm, especially among women and girls in Eastern Mediterranean countries $[2,15]$.

The high prevalence rate (table 1) observed in this study confirmed the results of previous studies [24, 25] because adolescence is a susceptible period to the initiation of tobacco use [26]. Water pipe smoking is associated with a cultural tradition and is considered a more socially acceptable activity than cigarette smoking. In many Middle Eastern countries, it is inappropriate for youth to smoke cigarettes in the presence of elders whereas water pipe smoking is allowed $[26,27]$. This issue highlights the importance of planning and implementing tobacco prevention and control policies among the younger generation in Iran.

In the present study, women with a university education were more likely to smoke a water pipe similar to previous studies $[4,28]$, most probably due to peer pressure $[5,6,26]$. Considering the fact that people find many friends at their university, it may follow that students smoke a water pipe as a way of spending their leisure time, and this may account for the higher prevalence of water pipe smoking among people with a university education. Educational interventions may be effective for helping smokers to quit [29].

Water pipe smoking was less frequent in families with low crowding; this observation is similar to that of Tamim et al. [22] as peers and family members smoke a water pipe together $[14,30]$. Smoking a water pipe is a common behaviour among family members of all ages in Middle Eastern families [22], and this may account for its more frequent use in larger families.

It must be noted that due to the cross-sectional nature of our study, the relationships observed between the prevalence of water pipe smoking and its associated factors do not necessarily indicate causation. In addition, the survey was limited to two items assessing water pipe tobacco smoking history: current smoking and duration of water pipe smoking. More items that provide detailed information regarding water pipe smoking patterns in this population will helpfully delineate water pipe smoking behaviors.

Because of the high prevalence of water pipe smoking among women with a university education and those aged 15-24 years, there is a need for public health control strategies in these groups, all the more so as water pipe smoking is known to have adverse health effects. 


\section{Conclusion}

The findings of this study indicate that Iranian women with a university education and younger age groups are at most risk for water pipe smoking. The findings of this study about associated factors may contribute to the development of efficient health promotion programmes for the prevention and cessation of water pipe smoking.

\section{Acknowledgments}

This study was funded and supported by Tehran University of Medical Sciences (TUMS); grant No. 89-02-28-10802. We would like to express our appreciation to those who participated in this study.

\section{References}

$\checkmark 1$ Rastam S, Ward KD, Eissenberg T, Maziak $\mathrm{W}$ : Estimating the beginning of the water pipe epidemic in Syria. BMC Public Health 2004;4:32.

2 Maziak W, Ward KD, Afifi Soweid RA, Eissenberg T: Tobacco smoking using a water pipe: a re-emerging strain in a global epidemic. Tob Control 2004;13:327-333.

3 Watad W, Sukhera J, Shushan S, Kazlak M, Skinner HA, Alnueirat AA, Roth Y: Water pipe smoking: effects, attitudes and directions. J Smok Cessat 2009;4:18-25.

4 Saadat S, Karbakhsh M: Association of water pipe smoking and road traffic crashes. BMC Public Health 2010;10:639.

5 Smith-Simone SY, Curbow BA, Stillman FA: Differing psychosocial risk profiles of college freshmen water pipe, cigar, and cigarette smokers. Addict Behav 2008;33:1619-1624.

6 Jackson D, Aveyard P: Water pipe smoking in students: prevalence, risk factors, symptoms of addiction, and smoke intake. Evidence from one British university. BMC Public Health 2008;8:174.

7 Cobb C, Ward KD, Maziak W, Shihadeh AL, Eissenberg T: Waterpipe tobacco smoking: an emerging health crisis in the United States. Am J Health Behav 2010;34:275-285.

-8 Sarrafzadegan N, Toghianifar N, Roohafza H, Siadat Z, Mohammadifard N, O'loughlin J: Lifestyle-related determinants of hookah and cigarette smoking in Iranian adults. J Community Health 2010;35:36-42.

-9 Tavafian SS, Aghamolaei T, Zare S: Water pipe smoking and health-related quality of life: a population-based study. Arch Iran Med 2009;12:232-237.

10 Al-Safi SA, Ayoub NM, Albalas MA, AlDoghim I, Aboul-Enein FH: Does shisha smoking affect blood pressure and heart rate? J Public Health 2009;17:121-126.

11 Ray CS: The hookah - the Indian water pipe. Curr Sci 2009;96:1319-1323.
2 Akl EA, Gaddam S, Gunukula SK, Honeine $\mathrm{R}$, Jaoude PA, Irani J: The effects of water pipe tobacco smoking on health outcomes: a systematic review. Int J Epidemiol. 2010;39: 834-857.

13 Aljarrah K, Ababneh ZQ, Al-Delaimy WK: Perceptions of hookah smoking harmfulness: predictors and characteristics among current hookah users. Tob Induc Dis 2009;5: 16.

14 Mohammed HR, Zhang Y, Newman IM, Shell DF: Water pipe smoking in Kuwait. East Mediterr Health J 2010;16:115-120.

15 Dar-Odeh NS, Bakri FG, Al-Omiri MK, AlMashni HM, Eimar HA, Khraisat AS, AbuHammad SMK, Dudeen AF, Nur Abdallah M, Alkilani SMZ, Al-Shami A, Abu-Hammad OA: Research narghile (water pipe) smoking among university students in Jordan: prevalence, pattern and beliefs. Harm Reduct J 2010;7:10.

16 Aghamolaei T, Tavafian SS, Zare S: Health related quality of life in elderly people living in Bandar Abbas, Iran: a population-based study. Acta Med Iran 2009;48:185-191.

17 Meysamie A, Ghaletaki R, Haghazali M, Asgari F, Rashidi A, Khalilzadeh O, Esteghamati A, Abbasi M: Pattern of tobacco use among the Iranian adult population: results of the national Survey of Risk Factors of Non-Communicable Diseases (SuRFNCD2007). Tob Control 2010;19:125-128.

18 Mirahmadizadeh A, Nakhaee N: Prevalence of water pipe smoking among rural pregnant women in southern Iran. Med Princ Pract 2008; 17:435-439.

19 Statistical Center of Iran: National Census of Population and Housing of Iran 2006. http:// amar.sci.org.ir.
20 World Health Organization: BMI classification. World Health Organization 2006. http:// apps.who.int $/ \mathrm{bmi} /$ index.jsp?introPage= intro_3.html.

21 Sahraian A, Sharifian M, Omidvar B, Javadpour A: Prevalence of substance abuse among the medical students in southern Iran. Shiraz E-Med J 2010;11:198-202.

22 Tamim H, Al-Sahab B, Akkary G, Ghanem M, Tamim N, El Roueiheb Z, Kanj M, Afifi $\mathrm{R}$ : Cigarette and nargileh smoking practices among school students in Beirut, Lebanon. Am J Health Behav 2007;31:56-63.

23 Labib N, Radwan G, Mikhail N, Mohamed MK, Setouhy ME, Loffredo C, Israel E: Comparison of cigarette and water pipe smoking among female university students in Egypt. Nicotine Tob Res 2007;9:591-596.

24 Jamil H, Elsouhag D, Hiller S, Arnetz JE, Arnetz BB: Socio-demographic risk indicators of hookah smoking among White Americans: a pilot study. Nicotine Tob Res 2010;12: 525-529.

25 Eissenberg T, Ward KD, Smith-Simone S, Maziak W: Water pipe tobacco smoking on a US college campus: prevalence and correlates. J Adolesc Health 2010;42:526-529.

26 Biswas AK, Sarkar J: Tobacco use among urban school boys of Paschim Midnapore, India. J Pak Med Assoc 2010;60:786-789.

27 Kandela P: Nargile smoking keeps Arabs in wonderland. Lancet 2000;356:1175.

28 Khami MR, Murtomaa H, Razeghi S, Virtanen JI: Smoking and its determinants among Iranian dental students. Med Princ Pract 2010;19:390-394.

29 Waheedi M, Al-Tmimy AM, Enlund H: Preparedness for the smoking cessation role among health sciences students in Kuwait. Med Princ Pract 2011;20:237-243.

30 Knishkowy B, Amitai Y: Water pipe (narghile) smoking: an emerging health risk behavior. Pediatrics 2005;116:113-119. 